\title{
ANÁLISE DOS PARTICIPANTES SOBRE A MENSURAÇÃO A VALOR JUSTO NOS CONTRATOS DE SEGURO
}

ANALYSIS OF PARTICIPANTS ON FAIR VALUE MEASUREMENT IN INSURANCE CONTRACTS

\author{
WANDERSON ARAÚJO FERNANDES \\ Universidade de Brasilia \\ MILLENA CORDEIRO DA SILVA \\ Universidade de Brasilia \\ JEREMIAS PEREIRA DA SILVA ARRAES \\ Universidade de Brasilia
}

Recebido em 23/11/18

Avaliado pelo sistema double blind review

Aceito para publicação pelo Editor Chefe Dr. Leonardo José Seixas Pinto em 04/12/18 e publicado em 28/12/18

\section{RESUMO}

O presente artigo faz uma análise dos participantes que responderam as cartas comentário proposto pelo Discussion Paper 2007 - Preliminary Views on Insurance Contracts em relação à mensuração a valor justo dos contratos de seguros. Foram levantadas 161 comments letters, em que se observou o nível de concordâncias das perguntas presente no capítulo 3 que trata de mensuração, os resultados apontam para uma concordância sobre a mensuração em três blocos, e uma discordância nas demais perguntas que trata sobre nível de detalhamento das explicações sobre fluxo de caixa e margem de risco, e sobre a definição e utilização do termo "Valor de Saída Atual". Sobre a calibração do prêmio cobrado em função da margem de risco, os participantes apoiam em sua maioria a opção que permite uma flexibilidade dessa calibragem na maioria dos casos, e surgindo um ganho ou perda significativa é aceitável seu reconhecimento desde que haja uma investigação.

Palavras-Chave: Valor Justo; Contratos de Seguros; Cartas comentário.

\section{ABSTRACT}

This article makes an analysis of the participants who responded to the comment letters proposed by the Discussion Paper 2007-Preliminary Views on insurance contracts in relation to the fair value measurement of insurance contracts. We raised 161 comments letters, in which we observed the level of concordances of the questions present in Chapter 3 that deals with measurement, the results point to a concordance on the measurement in three blocks, and a disagreement in the other questions Which deals with the level of detailing of explanations about cash flow and margin of risk, and on the definition and use of the term "current output value". On the calibration of the premium levied on the basis of the risk margin, the participants mostly support the option that allows for a flexibility of this calibration in most cases, and a significant gain or loss is acceptable if their recognition There's an investigation.

Keywords: Fair Value; Insurance contracts; Comment Letters. 


\section{INTRODUÇÃO}

A forma como os elementos patrimoniais são mesurados tem-se apresentado como um atributo necessário para o registro dos fenômenos contábeis. Conforme apresentado por Niyama (2014, p.95) a mensuração representa um importante aspecto da teoria da contabilidade, podendo ser definida como um processo de atribuição de números a objetos ou eventos, de acordo com regras prescritas (STEVENS, 1951).

Com relação à mensuração contábil Hendriksen e Van Breda (1999) definem como o processo de atribuição de valores monetários significativos a objetos ou eventos associados a uma empresa, e obtidos de modo a permitir agregação (tal como na avaliação total de ativos) ou desagregação, quando exigida em situações específicas. A respeito da importância da mensuração Ijiri (1970) comenta que é a competência central da contabilidade, e que sem o entendimento do que é mensurado e como é mensurado, é totalmente impossível uma apropriada compreensão da contabilidade.

Sob essa ótica, o IASB (International Accounting Standards Board) órgão internacional de emissão de normas contábeis tem levado a questionamentos sobre a forma de mensuração de alguns elementos patrimoniais. Em destaque, em seu Discussion Paper (DP) de maio de 2007 que trata de contratos de seguros, o órgão busca por meio dos comments letters melhorias ao atual modelo de reconhecimento, mensuração e evidenciação dos contratos de seguro.

Após de um extenso trabalho realizado na Fase 1, que começou em 1997 e na Fase 2 do IFRS 4 - Insurance Contracts que teve seu início em maio de 2007, o IASB em maio de 2017 finaliza esse trabalho o com emissão da IFRS 17 - Insurance Contracts. Essa norma, entre outras, estabelece os passos para a mensuração dos contratos de seguros. Assim quando o IASB iniciou os trabalhos na Fase 2 dos contratos de seguro, tinha como objetivo desenvolver um modelo de mensuração de ativos e passivos, no qual os ativos e passivos decorrentes de contratos de seguro seriam reconhecidos por seu valor justo (BLOOMER, 2004).

Sendo considerado o mais útil nas características de mercado, o valor justo atende as preocupações reportadas pelo processo de mensuração, tendo sido escolhido como a solução preferida no interminável tradeoff entre confiabilidade e relevância das informações contábeis (PROCHÁZKA, 2011). A maioria dos debates sobre o valor justo incide em questões técnicas, particularmente em como aplicar o valor justo a responsabilidades para as quais não existem valores de mercado. Apesar dos assuntos técnicos serem importantes, a verdadeira direção deverá ser na melhoria da transparência das demonstrações financeiras (DIAS, 2005).

Atualmente, o valor justo virou realidade em diversos ramos da contabilidade, sendo que alguns autores, através de seus trabalhos, aprovam (Barth, 2008; Barth e Taylor, 2009; Barth et al, 2001; Procházka, 2011; Montague, 2010) e outros não concordam com a tal metodologia de mensuração (KING, 2009).

Diante do exposto, torna-se relevante a observação do mercado para esta forma de mensuração, formulando-se assim a seguinte questão: Qual a percepção do mercado sobre a proposta de mensuração dos contratos de seguros informados nas comments letters enviadas a partir do DP de 2007?

O objetivo da pesquisa consiste em: (i) Identificar a percepção do mercado sobre os conceitos e termos apresentados no DP relativo à mensuração dos contratos de seguros; (ii) Identificar o nível de concordância ou discordância sobre as propostas de mensuração dos contratos de seguros; (iii) Comparar os conceitos de valor justo disseminados pela literatura em relação aos conceitos propostos pelo DP a partir da análise das cartas comentários enviadas pelo mercado sobre os questionamentos relativos à mensuração dos contratos de seguros.

\section{FUNDAMENTAÇAO TEÓRICA}

\subsection{Valor Justo}

Um dos primeiros indícios da utilização do termo "Valor Justo" foi em 1898 na sentença no caso Smith vs Ames, dada pela Suprema Corte dos EUA, em favor dos acionistas de uma companhia ferroviária em obter um retorno justo dos investimentos, e que esse só poderia ser calculado sobre o "valor justo da propriedade" (MCCARTY, 1915, apud, Marques 2017). Um segundo momento da 
utilização do termo se deu no trabalho de Moonitz (1961) com o conceito de valor de marcado e mais tarde Sprouse e Moonitz (1962) utilizam o conceito de preço de mercado.

O conceito de valor justo passa a ser utilizado com mais frequência nas décadas de 1960 e 1970, dado ao período inflacionário ocorrido na época, sendo mais recentemente utilizado para avaliação de vários ativos e passivos, principalmente ligados a instrumentos financeiros.

O FASB utilizou o termo pela primeira vez em 1975 na Financial Accounting Stadards $n^{\circ} 8$ (FAS 8) - Accounting for the Translation of Foreign Currency Transactions and Foreign Currency Financial Statements, sendo depois utilizada em mais outras 42 normas (MARQUES, 2017). Assim, entre algumas modificações estruturais na definição de valor justo tanto o FASB (SAFS 157) quanto o IASB (IFRS 13) trazem a seguinte definição de valor justo: o preço que seria recebido para vender um ativo ou pago para transferir um passivo em uma transação normal entre participantes do mercado na data da mensuração.

Com relação à mensuração a valor justo o IASB e o FASB propõem o estabelecimento de uma estrutura a ser seguida de acordo com o nível de confiabilidade e quanto aos métodos e técnicas de avaliação utilizados na mensuração (FORNARO; BARBERA, 2007).

De forma resumida, para garantir a comparabilidade da mensuração a valor justo atualmente tem-se uma hierarquia em três níveis, sendo o nível 1 e nível 2 utilizados para aqueles insumos observados e o nível 3 para insumos não observados. Assim o nível 1 deve ser utilizado para mensurar um ativo ou passivo em que é possível observar que o item avaliado possui dados que refletem preços em um mercado ativo. O nível 2 são utilizados quando não há itens de ativos e passivos idênticos, mas similares em um mercado ativo. E para o nível 3 como não existem dados observados, serão utilizadas informações internas da empresa para estabelecer um valor justo.

As propostas do IASB e do FASB indicam uma clara preferência pelo uso de valores de mercado observados sobre as estimativas de avaliação. Além disso, se as estimativas de avaliação forem utilizadas, os métodos para desenvolver essas estimativas devem ser consistentes com o mercado (CAS FAIR VALUE STEERING COMMITTEE, 2004). O FASB indica explicitamente que todas as estimativas de valor justo devem maximizar os insumos do mercado (preços de mercado observáveis e premissas do mercado) provenientes do mercado de referência apropriado e, em geral, quanto mais insumos de mercado utilizam mais confiável é a estimativa.

Com relação ao nível 3, estudos têm apresentado evidencias de manipulação dos dados utilizados para fazer estimativas para fins de Gerenciamento de Resultado, já que não existe um mercado ativo a ser observável. Para minimizar tais problemas os órgãos normatizadores exigem um maior detalhamento a ser evidenciado, tanto qualitativa como quantitativamente, com o objetivo de tornar mais transparente a mensuração a valor justo em nível 3 (RYAN, 2008).

Cristea (2015) elenca alguns benefícios ou vantagens na mensuração a valor justo:

- Agrega valor às decisões da empresa;

- Reduz a complexidade, ressaltando que a implementação é simples para instrumentos financeiros de curto prazo;

- Melhora a comparabilidade, pois permite fornecer valores comparáveis de instrumentos financeiros equivalentes;

- Melhora a neutralidade, pois é determinado por referências externas ou diretamente em valores de mercado, ou ainda na ausência de um mercado ativo para referência, utiliza-se um modelo com base nos parâmetros de dados externos, sendo dessa forma neutro por não ser influenciado pela empresa.

Porém os opositores a utilização do valor justo como base de mensuração apresentam críticas, conforme apresentado por Marques, 2017:

- Não é relevante;

- Os preços podem ser distorcidos pelas ineficiências do mercado, pela irracionalidade dos investidores ou por problemas de liquidez;

- Os valores de mercado com base em modelos não são confiáveis; 
- Contribuem para os problemas de pró-ciclicidade, agravando as oscilações no sistema financeiro;

- Chegar no valor "real" é altamente subjetivo; e

- Sem mercado ativo, seria impossível determinar o valor justo para determinados instrumentos financeiros, o que pode tornar as demonstrações financeiras enganosas.

Dento desse contexto a implementação de um sistema de contabilidade de valor justo sempre se mostrou problemática, seja na avaliação de instalações e equipamentos, seja em instrumentos financeiros (BLOOMER, 2004).

Os esforços dos órgãos normatizadores para impulsionar a contabilização do valor justo em instrumentos financeiros se deu no início dos anos 90 com preocupação na contabilização de derivativos para depois serem ampliados para cobrir todos os instrumentos financeiros. Era evidente, desde o início, que qualquer contabilização do valor justo para os instrumentos financeiros precisaria cobrir as transações tanto dos bancos comerciais como também das companhias de seguros. Como resultado, foi necessário cobrir transações que vão desde empréstimos bancários e depósitos através de contratos de seguro até os principais contratos comerciais de resseguro.

\subsection{Valor Justo nos Contratos de Seguros}

Bloomer (2004) argumenta que existem duas questões-chave em relação à contabilidade a valor justo e ao seguro. A primeira é a definição de contratos de seguro e a segunda, se é viável usar o valor justo para um contrato de seguro. A definição de contrato de seguro para que possa ser diferenciada de outros instrumentos financeiros tem sido um problema significativo.

Nesse sentido o IASB na IFRS 17 - Insurance Contracts traz a seguinte definição de contrato de seguro: Contrato segundo o qual uma das partes (o emissor) aceita o risco de seguro significativo de outra parte (o tomador do seguro) concordando em compensar o tomador do seguro se um evento futuro incerto especificado (o evento segurado) afetar negativamente o tomador da apólice.

E ainda especifica quando um contrato de seguro possui característica de participação direta: Um contrato de seguro para o qual, no início:

a) os termos contratuais especificam que o segurado participa de uma parcela de um conjunto claramente identificado de itens subjacentes;

b) a entidade espera pagar ao segurado um valor igual a uma parcela substancial do retorno do valor justo nos itens subjacentes; e

c) a entidade espera que uma proporção substancial de qualquer alteração nos valores a serem pagos ao tomador de apólices varie de acordo com a variação no valor justo dos itens subjacentes.

Ainda segundo a IFRS 17, itens subjacentes são aqueles que determinam alguns dos valores a pagar a um tomador de seguro. Os itens subjacentes podem incluir quaisquer itens; por exemplo, um portfólio de referência de ativos, o patrimônio líquido da entidade ou um subconjunto específico do patrimônio líquido da entidade.

Pode-se verificar que a definição de contrato de seguro com características diretas inclui o termo valor justo, entretanto, a questão de usar uma abordagem de valor justo para os contratos de seguro é complexa nos seguintes pontos (VANDERHOOF e ALTMAN, 2013):

1. Como estimar valores de mercado de ativos e passivos que não possuem mercado ativo e liquido?

2. A utilização de fluxo de caixa descontado a uma taxa adequada como alternativa de não haver um mercado ativo, pode ser utilizado? Mas haveria problemas em determinar a taxa de desconto apropriada ou qualquer ajuste ao fluxo de caixa?

3. Os contratos de seguro de vida podem ser muito longos e existem restrições sobre as empresas que abandonam contratos antecipadamente para por outros mais rentáveis. Isso requer um sistema de contabilidade que não apenas situe os valores justos nos passivos não negociados de longo prazo, mas também deve ser capaz de 
medir consistentemente os valores justos para os ativos não negociados de longo prazo associados a esses passivos.

4. Os riscos de seguro para algumas classes de negócios são particularmente difíceis de prever e, historicamente, as seguradoras detém capital adicional para cobrir essas incertezas. Isso pode ser feito através da construção de margens extras, explícitas ou implícitas, em provisões para pagamentos de reivindicações futuras.

5. Ao se reunirem, as seguradoras são capazes de diversificar riscos dentro de um portfólio tanto em produtos como também ao longo do tempo. Esse efeito de portfólio não é capturado por modelos baseados em transações individuais.

A lista acima não se destina a ser uma discussão exaustiva das questões e problemas em torno da contabilidade de valor justo. No entanto, qualquer sistema de contabilidade que não lida com essas questões pode não refletir a substância econômica subjacente ao negócio.

\section{METODOLOGIA DE PESQUISA}

Com relação à característica dessa pesquisa é do tipo descritiva, utilizando uma abordagem qualitativa, com pesquisa documental, por meio de análise de conteúdo. A pesquisa é qualitativa pois dela faz parte a obtenção de dados descritivos mediante contato direto e interativo do pesquisador com a situação objeto de estudo. Nas pesquisas qualitativas, é frequente que o pesquisador procure entender os fenômenos, segundo a perspectiva dos participantes da situação estudada e, a partir, daí situe sua interpretação dos fenômenos estudados (NEVES, 1996). E como forma utiliza-se a pesquisa documental como sendo constituída pelo exame de materiais que ainda não receberam um tratamento analítico ou que podem ser reexaminados com vistas a uma interpretação nova ou complementar.

Com relação a análise de conteúdo Bandin (2011) infere que a função primordial da análise do conteúdo é o desvendar crítico em que o estudo sobre análise do conteúdo visa incidir em diferentes fontes de dados, são elas: material jornalístico, discursos políticos, cartas, publicidades, romances e relatórios oficiais. A análise de conteúdo aparece como um conjunto de técnicas de análise das comunicações que utiliza procedimentos sistemáticos e objetivos de descrição do conteúdo das mensagens.

\section{COLETA E ANÁLISE DOS DADOS}

Para os objetivos dessa pesquisa procedeu a coleta de dados e em duas frentes: a) o Discussion Paper - Preliminary Views on Insurance Contracts (DP/2007/1); b) a coleta das comments letters, que contém as opiniões dos respondentes sobre o conteúdo apresentado na DP/2007/1.

O DP/2007/1 está dividido da seguinte forma: PARTE 1 com o Capitulo 1 - Antecedentes, Capítulo 2 - Reconhecimento e (Des)reconhecimento, Capítulo 3 - Mensuração, questões básicas, Capítulo 4 - Comportamento do segurado, relacionamento com o cliente e custos de aquisição, Capítulo 5 - Mensuração, outras questões, Capítulo 6 - Participação dos segurados, Capítulo 7 Alteração nos passivos de seguros; Parte 2 com Apêndices.

Para a pesquisa foram selecionadas as questões apresentadas no capitulo 3 - Mensuração, questões básicas, conforme demonstrado no Quadro 1. 
Quadro 1: Perguntas dos capitulo 3 do DP/2007/1

\begin{tabular}{|c|c|}
\hline \multirow{4}{*}{$\begin{array}{l}\text { Pergunta } \\
2\end{array}$} & $\begin{array}{l}\text { Se uma seguradora mensurasse todos os seus passivos de seguros usando os três blocos de } \\
\text { construção a seguir: }\end{array}$ \\
\hline & $\begin{array}{l}\text { a) estimativas explícitas, imparciais, consistentes em mercado, ponderadas pela probabilidade e dos } \\
\text { fluxos de caixa atuais do contratuais; }\end{array}$ \\
\hline & $\begin{array}{l}\text { b) taxas de desconto atuais do mercado que ajustam os fluxos de caixa futuros estimados para o } \\
\text { valor do tempo do dinheiro e; }\end{array}$ \\
\hline & $\begin{array}{l}\text { c) uma estimativa explícita e imparcial da margem que os participantes do mercado exigem para } \\
\text { suportar risco (uma margem de risco) e para fornecer outros serviços, se houver (uma margem de } \\
\text { serviço)? Caso contrário, qual abordagem você propõe e por quê? }\end{array}$ \\
\hline $\begin{array}{l}\text { Pergunta } \\
\quad 3\end{array}$ & $\begin{array}{l}\text { As orientações presentes na minuta sobre os fluxos de caixa (apêndice E) e as margens de risco } \\
\text { (apêndice F) estão no nível certo de detalhe? Alguma dessas orientações deve ser modificada, } \\
\text { excluída ou estendida? Por que ou por que não? }\end{array}$ \\
\hline \multirow{5}{*}{$\begin{array}{l}\text { Pergunta } \\
4\end{array}$} & $\begin{array}{l}\text { Qual o papel do prêmio real cobrado pela seguradora na calibração das margens e por quê? Diga } \\
\text { quais das seguintes alternativas que você apoia. }\end{array}$ \\
\hline & $\begin{array}{l}\text { a) A seguradora deve calibrar a margem diretamente para o prêmio real (custos de aquisição), } \\
\text { sujeito a um teste de adequação do passivo. Como resultado, uma seguradora nunca deve } \\
\text { reconhecer um lucro no início de um contrato de seguro. }\end{array}$ \\
\hline & $\begin{array}{l}\text { b) Deve haver uma presunção refutável de que a margem implícita pelo prêmio real (custos de } \\
\text { aquisição) é consistente com a margem que os participantes do mercado exigem. Se você preferir } \\
\text { essa abordagem, quais evidências devem ser necessárias para refutar a presunção? }\end{array}$ \\
\hline & $\begin{array}{l}\text { c) O prémio (custos de aquisição) pode ser calibrada pela margem que os participantes do mercado } \\
\text { exigiriam, mas não tem status superior a outras evidências possíveis. Na maioria dos casos, os } \\
\text { contratos de seguro devem fornecer uma margem consistente com os requisitos dos participantes do } \\
\text { mercado. Portanto, se um lucro ou perda significativa parece surgir no início, é necessária uma } \\
\text { investigação mais aprofundada. No entanto, se a seguradora concluir, após uma investigação } \\
\text { posterior, que o preço de mercado estimado para o risco e o serviço difere do preço implícito nos } \\
\text { prêmios que cobra, a seguradora reconheceria um lucro ou perda no início. }\end{array}$ \\
\hline & d) Outro (especifique). \\
\hline \multirow{3}{*}{$\begin{array}{l}\text { Pergunta } \\
5\end{array}$} & $\begin{array}{l}\text { Este documento propõe que o atributo de mensuração para passivos de seguros deve ser o valor que } \\
\text { a seguradora esperaria pagar na data do aviso para transferir imediatamente seus direitos e } \\
\text { obrigações contratuais para outra entidade. Este documento rotula esse atributo de mensuração } \\
\text { 'valor de saída atual'. }\end{array}$ \\
\hline & $\begin{array}{l}\text { (a) Esse atributo de mensuração é apropriado para passivos de seguros. Por que ou por que não? } \\
\text { Caso contrário, qual atributo de mensuração você sugere e por quê? }\end{array}$ \\
\hline & $\begin{array}{l}\text { (b) O "valor de saída atual" é o melhor rótulo para esse atributo de mensuração? Por que ou por que } \\
\text { não? }\end{array}$ \\
\hline
\end{tabular}

Fonte: IASB (2007)

Foram coletadas as Comments Letters, contendo as opiniões gerais dos respondentes independente do capítulo em que foram respondidas as questões propostas do DP/2007/1. Foram obtidas todas as cartas envias ao IASB, dentro do prazo estipulado, até 16 de novembro de 2007. Chegou-se ao levantamento de 162 comments letters, sendo que uma delas não foi possível verificar seu conteúdo, sendo analisado, portanto 161 cartas.

\section{ANÁLISE DAS COMMENTS LETTERS}

Os dados foram tabulados de forma a categorizar as cartas de acordo com o tipo de usuário que respondeu ou opinou, setor de atuação, país de origem do respondente, continente de origem e quantidade de cartas respondidas.

A análise das cartas procedeu após a tabulação das 161 cartas de acordo com as perguntas apresentadas no capítulo 3 do DP/2007/1. A construção do instrumento de pesquisa foi realizada de forma qualitativa, mas a análise deste instrumento foi realizada de forma quantitativa e a apresentação dos resultados também procedeu da mesma forma.

Com relação a leitura das respostas contidas nas cartas comentário foram de acordo com a sequência dos documentos disponibilizados pelo sitio do IASB, e foram lidas integralmente as 
respostas que fazem referência as questões de 2 a 5 do capítulo 3 do DP. As respostas foram classificadas das seguintes maneiras: a) para as perguntas 2 e 5 analisou-se se o respondente concordava, concordava parcialmente ou discordava do tema proposto; b) para a pergunta 3 verificouse se a adequação das informações incluídas no DP; c) para a pergunta 4, verificou qual das opções o respondente teve preferência, e; d) para a pergunta 5 verificou-se também qual a sugestão ou embasamento utilizado na sua resposta. Os procedimentos metodológicos dessa pesquisa foram embasados no trabalho realizado por Silva (2015), que realizou a pesquisa das comments letters em relação a proposta da revisão da estrutura conceitual do IASB de 2013, com adaptação em relação a categorização.

\section{ANÁLISE DOS RESULTADOS}

Até a última etapa, quando instituída a norma IFRS 17 - Insurance Contracts, partindo do início da fase 2 do projeto após a divulgação da IFRS 4, foram dez anos. Nesse período ainda percorreu um caminho conforme visto na Figura 1.

Figura 1: Evolução histórica da Fase 2 de Contratos de Seguros

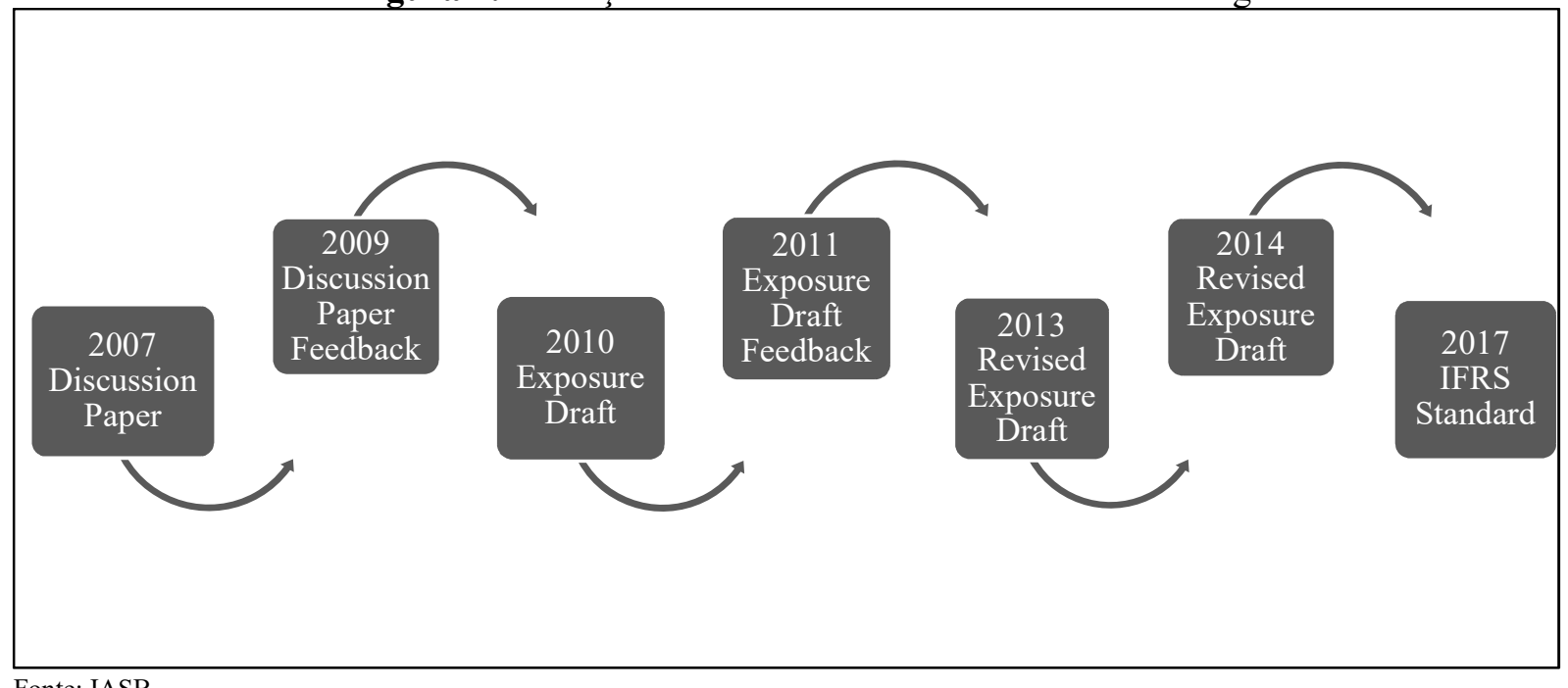

Assim foram analisadas as respostas das comments letters referente às questões propostas pelo DP/2007/1, pela razão de verificar a percepção dos respondentes que poderiam ser acometidos por vieses em suas respostas após a divulgação do retorno (feedback) do DP em 2009 ou nos períodos seguintes. Apesar da versão final já está publicada a pesquisa limita-se a comparação das respostas ou opiniões com os conceitos preconizados pela literatura presente na teoria contábil.

\subsection{Perfil dos Respondentes}

As cartas foram classificadas por setor de atuação e localização (país e continente), conforme pode ser observado no quadro abaixo há uma concentração de respondentes nos EUA (22,98\%), Reino Unido $(21,12 \%)$, Austrália $(9,32 \%)$ e Canadá $(5,59)$ perfazendo um total de $59,01 \%$. Com relação a maioria das cartas respondidas o estudo de Silva (2015) obteve os mesmos resultados numa amostra de 80 comments letters. 
Quadro 2: Quantidade de respostas por país de origem

\begin{tabular}{|c|l|c|c|c|l|c|c|}
\hline Seq. & País & Quant. & $\mathbf{\%}$ & Seq. & País & Quant. & \% \\
\hline 1 & África do Sul & 8 & $4,97 \%$ & 15 & EUA & 37 & $22,98 \%$ \\
\hline 2 & Alemanha & 5 & $3,11 \%$ & 16 & França & 7 & $4,35 \%$ \\
\hline 3 & Austrália & 15 & $9,32 \%$ & 17 & Holanda & 2 & $1,24 \%$ \\
\hline 4 & Áustria & 1 & $0,62 \%$ & 18 & Irlanda & 2 & $1,24 \%$ \\
\hline 5 & Bélgica & 4 & $2,48 \%$ & 19 & Itália & 1 & $0,62 \%$ \\
\hline 6 & Bermudas & 3 & $1,86 \%$ & 20 & Japão & 6 & $3,73 \%$ \\
\hline 7 & Brasil & 1 & $0,62 \%$ & 21 & Malásia & 1 & $0,62 \%$ \\
\hline 8 & Canadá & 9 & $5,59 \%$ & 22 & México & 1 & $0,62 \%$ \\
\hline 9 & República Checa & 1 & $0,62 \%$ & 23 & Noruega & 1 & $0,62 \%$ \\
\hline 10 & China & 1 & $0,62 \%$ & 24 & Nova Zelândia & 5 & $3,11 \%$ \\
\hline 11 & Coreia do Sul & 2 & $1,24 \%$ & 25 & Reino Unido & 34 & $21,12 \%$ \\
\hline 12 & Dinamarca & 2 & $1,24 \%$ & 26 & Singapura & 1 & $0,62 \%$ \\
\hline 13 & Escócia & 1 & $0,62 \%$ & 27 & Suécia & 4 & $2,48 \%$ \\
\hline 14 & Espanha & 2 & $1,24 \%$ & 28 & Suíça & 4 & $2,48 \%$ \\
\hline & & & & & Total geral & $\mathbf{1 6 1}$ & $\mathbf{1 0 0 \%}$ \\
\hline
\end{tabular}

Fonte: Dados da Pesquisa

Em relação ao continente dos respondentes pode-se verificar uma concentração na Europa, América do Norte, seguido da Oceania $(44,10 \%, 29,19 \%$ e 12,42\% respectivamente), reflexo do número da maioria dos países respondentes.

Quadro 3: Quantidade de respostas por continente de origem

\begin{tabular}{|c|l|c|c|}
\hline Seq. & País & Quant. & $\mathbf{\%}$ \\
\hline 1 & África & 8 & $4,97 \%$ \\
\hline 2 & América Central & 3 & $1,86 \%$ \\
\hline 3 & América do Norte & 47 & $29,19 \%$ \\
\hline 4 & América do Sul & 1 & $0,62 \%$ \\
\hline 5 & Ásia & 11 & $6,83 \%$ \\
\hline 6 & Europa & 71 & $44,10 \%$ \\
\hline 7 & Oceania & 20 & $12,42 \%$ \\
\hline & Total geral & $\mathbf{1 6 1}$ & $\mathbf{1 0 0 , 0 0 \%}$ \\
\hline
\end{tabular}

Fonte: Dados da Pesquisa

A classificação por setor de atuação pode-se observar os maiores percentuais em Associações Profissionais (34,78\%), Empresas (27,33\%) e Normatizadores (27,33\%). O setor de atuação classificado como "Empresas" estão ligadas em sua maioria ao setor de seguro, saúde, ou serviços financeiros, fora desses setores estão uma empresa de turismo, uma empresa de tabaco e uma da área automobilística.

Quadro 4: Quantidade de respostas por setor de atuação
\begin{tabular}{|c|l|c|r|}
\hline Seq. & País & Quant. & \multicolumn{1}{c|}{$\%$} \\
\hline 1 & Associação Profissional & 56 & $34,78 \%$ \\
\hline 2 & Auditoria & 6 & $3,73 \%$ \\
\hline 3 & Normatizadores & 44 & $27,33 \%$ \\
\hline 4 & Empresa & 44 & $27,33 \%$ \\
\hline 5 & Rating & 2 & $1,24 \%$ \\
\hline 6 & Universidade & 1 & $0,62 \%$ \\
\hline 7 & Usuário & 8 & $4,97 \%$ \\
\hline & Total Geral & $\mathbf{1 6 1}$ & $\mathbf{1 0 0 , 0 0 \%}$ \\
\hline
\end{tabular}

Fonte: Dados da Pesquisa 


\subsection{Análise das Perguntas do DP/2007/1}

A análise das perguntas foi considerada todas as cartas inclusive as que não responderam diretamente as perguntas propostas, nesse caso foi classificado como "Sem Comentário". A Pergunta 2 do Discursion Paper com relação ao nível de concordância analisado por setor de atuação verificase que $21,12 \%$ dos respondentes não opinaram sobre a questão. Dos respondentes há um maior consenso em considerar a mensuração de passivos em três blocos com destaque para empresas de auditoria e normatizadores, entre as Associações Profissionais e Empresas tiveram percentuais próximos apesar de concordarem na sua maioria, alguns dos questionamentos era a aplicação na prática quando da aplicação do fluxo de caixa descontado, como destaca uma empresa de seguros da Austrália: "Embora concordemos com a noção teórica de que os passivos devem ser mensurados aos preços de mercado observados, questionamos se isso é sempre realizável na prática".

Quadro 5: Nível de concordância por setor de atuação da Pergunta 2

\begin{tabular}{|c|c|c|c|c|c|c|c|c|c|}
\hline \multirow{2}{*}{$\begin{array}{l}\text { Setor de } \\
\text { Atuação }\end{array}$} & \multicolumn{4}{|c|}{ \% Com relação ao Nível de Concordância } & \multicolumn{4}{|c|}{$\begin{array}{l}\text { \% Nível de Concordância em relação ao Setor } \\
\text { de Atuação }\end{array}$} & \multirow[b]{2}{*}{ Total } \\
\hline & Concordo & Parcial & Discordo & $\begin{array}{c}\text { Sem } \\
\text { Comentário }\end{array}$ & Concordo & Parcial & Discordo & $\begin{array}{c}\text { Sem } \\
\text { Comentário } \\
\end{array}$ & \\
\hline $\begin{array}{l}\text { Associação } \\
\text { Profissional }\end{array}$ & $31,75 \%$ & $36,84 \%$ & $26,92 \%$ & $44,12 \%$ & $35,71 \%$ & $25,00 \%$ & $12,50 \%$ & $26,79 \%$ & 56 \\
\hline Auditoria & $7,94 \%$ & $0,00 \%$ & $3,85 \%$ & $0,00 \%$ & $83,33 \%$ & $0,00 \%$ & $16,67 \%$ & $0,00 \%$ & 6 \\
\hline Normatizadores & $36,51 \%$ & $23,68 \%$ & $11,54 \%$ & $26,47 \%$ & $52,27 \%$ & $20,45 \%$ & $6,82 \%$ & $20,45 \%$ & 44 \\
\hline Empresas & $20,63 \%$ & $36,84 \%$ & $42,31 \%$ & $17,65 \%$ & $29,55 \%$ & $31,82 \%$ & $25,00 \%$ & $13,64 \%$ & 44 \\
\hline Rating & $1,59 \%$ & $2,63 \%$ & $0,00 \%$ & $0,00 \%$ & $50,00 \%$ & $50,00 \%$ & $0,00 \%$ & $0,00 \%$ & 2 \\
\hline Universidade & $0,00 \%$ & $0,00 \%$ & $3,85 \%$ & $0,00 \%$ & $0,00 \%$ & $0,00 \%$ & $100,00 \%$ & $0,00 \%$ & 1 \\
\hline Usuário & $1,59 \%$ & $0,00 \%$ & $11,54 \%$ & $11,76 \%$ & $12,50 \%$ & $0,00 \%$ & $37,50 \%$ & $50,00 \%$ & 8 \\
\hline Total Geral & $100 \%$ & $100 \%$ & $100 \%$ & $100 \%$ & $39,13 \%$ & $23,60 \%$ & $16,15 \%$ & $21,12 \%$ & 161 \\
\hline
\end{tabular}

Fonte: Dados da Pesquisa

Em nível de concordância verifica-se certo equilíbrio, não sendo possível enfatizar a predominância a favor ou contra a utilização em três blocos para a mensuração do passivo de seguros. Com relação ao país de origem observa-se entre aqueles uma ligeira discordância nos EUA e quanto ao Reino Unido uma concordância parcial ou discordância muito próxima.

Quadro 6: Nível de concordância dos maiores respondentes por país de origem da Pergunta 2

\begin{tabular}{|c|c|c|c|c|c|c|c|c|c|}
\hline \multirow[b]{2}{*}{$\begin{array}{l}\text { País de } \\
\text { Origem }\end{array}$} & \multicolumn{4}{|c|}{ \% Com relação ao nível de concordância } & \multicolumn{4}{|c|}{$\begin{array}{c}\text { \% de Concordância em relação ao País de } \\
\text { Origem }\end{array}$} & \multirow[b]{2}{*}{ Total } \\
\hline & $\begin{array}{c}\text { Concord } \\
\quad 0\end{array}$ & Parcial & $\begin{array}{l}\text { Discord } \\
\quad 0\end{array}$ & $\begin{array}{c}\text { Sem } \\
\text { Comentári } \\
0 \\
\end{array}$ & Concordo & $\begin{array}{l}\text { Parcia } \\
\quad 1\end{array}$ & $\begin{array}{c}\text { Discord } \\
\quad 0\end{array}$ & $\begin{array}{c}\text { Sem } \\
\text { Comentári } \\
0 \\
\end{array}$ & \\
\hline Austrália & $18 \%$ & $14 \%$ & $5 \%$ & $24 \%$ & $40 \%$ & $20 \%$ & $7 \%$ & $33 \%$ & 15 \\
\hline Canadá & $21 \%$ & $5 \%$ & $0 \%$ & $5 \%$ & $78 \%$ & $11 \%$ & $0 \%$ & $11 \%$ & 9 \\
\hline EUA & $24 \%$ & $48 \%$ & $55 \%$ & $38 \%$ & $22 \%$ & $27 \%$ & $30 \%$ & $22 \%$ & 37 \\
\hline Reino Unido & $36 \%$ & $33 \%$ & $40 \%$ & $33 \%$ & $35 \%$ & $21 \%$ & $24 \%$ & $21 \%$ & 34 \\
\hline Total Geral & $100 \%$ & $100 \%$ & $100 \%$ & $100 \%$ & $35 \%$ & $22 \%$ & $21 \%$ & $22 \%$ & 95 \\
\hline
\end{tabular}

Fonte: Dados da Pesquisa

A Pergunta 3 sobre a opinião quanto ao nível de detalhes constantes nos apêndices E e F é possível verificar que das 161 cartas 89 foram respondidas destacando as empresas de auditoria em sua maior parte considerando como suficiente, porém os normatizadores e associações profissionais consideram insuficientes. A quantidade de cartas que não responderem a questão (72) pode está relacionado com as opiniões dos respondentes (30 deles) em que, independentemente da opinião quanto a proposta, observaram que explicações detalhadas estaria se distanciando do objetivo do IASB em trabalhar com padrões baseados em princípios e não regras, a "American Insurance Association (AIA) acredita que os apêndices E e F são muito detalhados para um padrão de contabilidade baseado em princípios. O IASB deve especificar o princípio geral de que os fluxos de caixa incluídos nos preços a ser incluídos na mensuração do passivo (apêndice E) e que, no início do 
contrato de seguro, a margem de risco deve ser calibrada ao prêmio cobrado de modo que não há ganho/perda".

Quadro 7: Nível de concordância por setor de atuação da Pergunta 3

\begin{tabular}{|l|c|c|c|c|c|c|c|}
\hline & \multicolumn{2}{|c|}{$\%$ Com relação ao Nível de Detalhes } & \multicolumn{2}{c|}{ Em relação ao Setor de Atuação } & \multicolumn{2}{c|}{ Sem } \\
\hline Setor de Atuação & Suficiente & Insuficiente & $\begin{array}{c}\text { Sem } \\
\text { Comentário }\end{array}$ & Suficiente & Insuficiente & Total \\
\hline Associação Profissional & $25,93 \%$ & $38,71 \%$ & $34,72 \%$ & $12,50 \%$ & $42,86 \%$ & $44,64 \%$ & 56 \\
\hline Auditoria & $18,52 \%$ & $1,61 \%$ & $0,00 \%$ & $83,33 \%$ & $16,67 \%$ & $0,00 \%$ & 6 \\
\hline Empresas & $22,22 \%$ & $22,58 \%$ & $33,33 \%$ & $13,64 \%$ & $31,82 \%$ & $54,55 \%$ & 44 \\
\hline Normatizadores & $33,33 \%$ & $30,65 \%$ & $22,22 \%$ & $20,45 \%$ & $43,18 \%$ & $36,36 \%$ & 44 \\
\hline Rating & $0,00 \%$ & $1,61 \%$ & $1,39 \%$ & $0,00 \%$ & $50,00 \%$ & $50,00 \%$ & 2 \\
\hline Universidade & $0,00 \%$ & $0,00 \%$ & $1,39 \%$ & $0,00 \%$ & $0,00 \%$ & $100,00 \%$ & 1 \\
\hline Usuário & $0,00 \%$ & $4,84 \%$ & $6,94 \%$ & $0,00 \%$ & $37,50 \%$ & $62,50 \%$ & 8 \\
\hline Total Geral & $100 \%$ & $100 \%$ & $100 \%$ & $16,77 \%$ & $38,51 \%$ & $44,72 \%$ & 161 \\
\hline
\end{tabular}

Fonte: Dados da pesquisa

Entre os países que tiveram maior número de respondentes observa-se maior destaque nos EUA em que $90 \%$ dos respondentes consideram as informações insuficientes, seguido do Canadá (71\%), isso pode ser explicado por estarem mais próximos das normas do FASB que traz seus pronunciamentos baseado em regras. A própria Securities and Exchange Commission (SEC) enfatiza que "a orientação sobre os fluxos de caixa no Apêndice E deve ser estendida para incluir os seguintes: (1) mais explicações e exemplos ilustrativos sobre como determinar uma estimativa do valor presente esperado dos fluxos de caixa gerados pelo contrato, (2) exemplos de Fluxos de caixa específicos de uma entidade referidos no parágrafo E27-E28, (3) significados e exemplos de todas as informações atuais disponíveis para variáveis de mercado e não-mercado, e (4) o Apêndice E 16 (b) precisa de mais esclarecimentos e exemplos sobre como determinar se as mudanças nas estimativas de probabilidades de cada cenário de fluxo de caixa representam fielmente alterações nas condições durante o período. A orientação sobre as margens de risco (Apêndice F) deve ser ampliada para incluir os seguintes: (1) definição de carteira na estimativa de margens de risco e (2) alguns exemplos do reconhecimento de margens de risco que levará ao reconhecimento de lucros ou prejuízos no início do contrato".

Quadro 8: Nível de concordância dos maiores respondentes por país de origem da Pergunta 3

\begin{tabular}{|l|c|c|c|c|c|}
\hline & \multicolumn{2}{|c|}{$\begin{array}{c}\text { \% Com relação ao } \\
\text { Nível de Detalhes }\end{array}$} & $\begin{array}{c}\text { Em relação ao País } \\
\text { de Origem }\end{array}$ & \\
\hline $\begin{array}{l}\text { País de } \\
\text { Origem }\end{array}$ & Suficiente & Insuficiente & Suficiente & Insuficiente & Total \\
\hline África do Sul & $19 \%$ & $10 \%$ & $43 \%$ & $57 \%$ & 7 \\
\hline Austrália & $13 \%$ & $10 \%$ & $33 \%$ & $67 \%$ & 6 \\
\hline Canadá & $13 \%$ & $12 \%$ & $29 \%$ & $71 \%$ & 7 \\
\hline EUA & $13 \%$ & $44 \%$ & $10 \%$ & $90 \%$ & 20 \\
\hline Reino Unido & $44 \%$ & $24 \%$ & $41 \%$ & $59 \%$ & 17 \\
\hline Total Geral & $100 \%$ & $100 \%$ & $28 \%$ & $72 \%$ & 57 \\
\hline
\end{tabular}

Fonte: Dados da Pesquisa

A Pergunta 4 solicita aos respondentes que indique uma das quatro alternativas apresentadas sobre a calibração das margens no prêmio real cobrado no contrato de seguro. No quadro abaixo "N" corresponde ao percentual de cartas que não responderam essa questão (38\%). A alternativa com maior percentual é a "C", porém observa-se que as opções " $A$ " e "D" possuem percentuais próximos na maioria dos setores, demonstrando uma falta de consenso dentro do próprio setor e a alternativa "B" como a menos aceita. 
Quadro 9: Escolha de alternativas propostas na Pergunta 4 por setor de atuação

\begin{tabular}{|c|c|c|c|c|c|c|c|c|c|c|c|}
\hline & \multicolumn{5}{|c|}{ \% de Respondentes por Alternativa } & \multicolumn{5}{|c|}{ \% de Alternativas por Setor de Atuação } & \multirow[b]{2}{*}{ Total } \\
\hline Setor de Atuação & $\mathbf{A}$ & B & $\mathbf{C}$ & D & $\mathbf{N}$ & $\mathbf{A}$ & B & $\mathbf{C}$ & D & $\mathbf{N}$ & \\
\hline Associação Profissional & $45 \%$ & $25 \%$ & $27 \%$ & $50 \%$ & $34 \%$ & $16 \%$ & $4 \%$ & $25 \%$ & $18 \%$ & $38 \%$ & 56 \\
\hline Auditoria & $0 \%$ & $13 \%$ & $8 \%$ & $5 \%$ & $0 \%$ & $0 \%$ & $17 \%$ & $67 \%$ & $17 \%$ & $0 \%$ & 6 \\
\hline Empresa & $25 \%$ & $25 \%$ & $23 \%$ & $25 \%$ & $33 \%$ & $11 \%$ & $5 \%$ & $27 \%$ & $11 \%$ & $45 \%$ & 44 \\
\hline Normatizadores & $30 \%$ & $38 \%$ & $37 \%$ & $20 \%$ & $20 \%$ & $14 \%$ & $7 \%$ & $43 \%$ & $9 \%$ & $27 \%$ & 44 \\
\hline Rating & $0 \%$ & $0 \%$ & $2 \%$ & $0 \%$ & $2 \%$ & $0 \%$ & $0 \%$ & $50 \%$ & $0 \%$ & $50 \%$ & 2 \\
\hline Universidade & $0 \%$ & $0 \%$ & $0 \%$ & $0 \%$ & $2 \%$ & $0 \%$ & $0 \%$ & $0 \%$ & $0 \%$ & $100 \%$ & 1 \\
\hline Usuário & $0 \%$ & $0 \%$ & $4 \%$ & $0 \%$ & $10 \%$ & $0 \%$ & $0 \%$ & $25 \%$ & $0 \%$ & $75 \%$ & 8 \\
\hline Total Geral & $100 \%$ & $100 \%$ & $100 \%$ & $100 \%$ & $100 \%$ & $12 \%$ & $5 \%$ & $32 \%$ & $12 \%$ & $38 \%$ & 161 \\
\hline
\end{tabular}

Fonte: Dados da Pesquisa

Entre os países que tiveram o maior número de respondentes verifica-se uma preferência também pela alternativa "C", indicando apenas o EUA por uma maior preferência pela opção "A", que sugere que deve haver uma calibração da margem, mas sujeitando-se ao teste de adequação do passivo e o não reconhecimento do lucro no início do contrato de seguros. Isso pode ser explicado por haver um maior conservadorismo das práticas contábeis do país. A alternativa "C" propõe um julgamento sobre calibrar o prêmio em função da margem sem, contudo, impor de forma definitiva o reconhecimento inicial de um lucro ou perda do contrato de seguro, devendo ser revisado.

Quadro 10: Escolha de alternativas propostas na Pergunta 4 por entre os maiores respondentes por país

\begin{tabular}{|l|c|c|c|c|c|c|c|c|c|}
\hline & \multicolumn{3}{|c|}{$\begin{array}{c}\text { \% de Respondentes por } \\
\text { Alternativa }\end{array}$} & \multicolumn{3}{c|}{$\begin{array}{c}\text { \% de Alternativas por País de } \\
\text { Origem }\end{array}$} \\
\hline País de Origem & A & B & C & D & A & B & C & D & Total \\
\hline África do Sul & $0 \%$ & $0 \%$ & $19 \%$ & $0 \%$ & $0 \%$ & $0 \%$ & $100 \%$ & $0 \%$ & 7 \\
\hline Austrália & $0 \%$ & $0 \%$ & $19 \%$ & $13 \%$ & $0 \%$ & $0 \%$ & $88 \%$ & $13 \%$ & 8 \\
\hline Canadá & $0 \%$ & $0 \%$ & $22 \%$ & $0 \%$ & $0 \%$ & $0 \%$ & $100 \%$ & $0 \%$ & 8 \\
\hline EUA & $83 \%$ & $40 \%$ & $14 \%$ & $25 \%$ & $53 \%$ & $11 \%$ & $26 \%$ & $11 \%$ & 19 \\
\hline Reino Unido & $17 \%$ & $60 \%$ & $27 \%$ & $63 \%$ & $10 \%$ & $15 \%$ & $50 \%$ & $25 \%$ & 20 \\
\hline Total Geral & $\mathbf{1 0 0} \%$ & $\mathbf{1 0 0} \%$ & $\mathbf{1 0 0} \%$ & $\mathbf{1 0 0} \%$ & $\mathbf{1 9 \%}$ & $\mathbf{8 \%}$ & $\mathbf{6 0 \%}$ & $\mathbf{1 3 \%}$ & $\mathbf{6 2}$ \\
\hline
\end{tabular}

Fonte: Dados da pesquisa

A Pergunta 5 trata da definição de "Valor de Saída Atual" e se esse seria o melhor termo a utilizar. Analisa-se, então, se os respondentes concordam ou não com as sugestões de definição e termo, e se haveria uma proposta com relação ao termo utilizado.

As seguintes propostas foram sugeridas para o termo "Valor de Saída Atual":

Quadro 11: Termos propostos pelos respondentes

\begin{tabular}{|c|l|}
\hline & Termos Propostos \\
\hline 1 & Valor de Liquidação \\
\hline 2 & Valor de Entrada Atual \\
\hline 3 & Valor Justo \\
\hline 4 & Valor de Liquidação Atual \\
\hline 5 & Valor de Saída \\
\hline 6 & Valor Econômico Atual \\
\hline 7 & Valor Final de Cumprimento \\
\hline 8 & Valor Atual de Liquidação \\
\hline 9 & Valor Atual da Saída Da Carteira \\
\hline 10 & Valor Liquido do Portfólio \\
\hline 11 & Preço de Transferência Hipotético \\
\hline 12 & Valor Atuarial \\
\hline 13 & Valor Atual \\
\hline 14 & Valor de Transferência Hipotético \\
\hline 15 & Valor de Transferência Atual Do Mercado \\
\hline 16 & Valor de Transferência Hipotético Estimado \\
\hline
\end{tabular}


Continua...

\begin{tabular}{|l|l|}
\hline 17 & Valor de Liquidação Final Atual, \\
\hline 18 & Valor de Extinção Atual \\
\hline 19 & Valor de Desempenho Atual \\
\hline 20 & $\begin{array}{l}\text { Valor de Saída Atual com Base em Fluxos de Caixa } \\
\text { Contratualmente Exigível }\end{array}$ \\
\hline 21 & Valor Presente Modelado de Passivos Do Seguro \\
\hline 22 & Valor Atual da Liquidação \\
\hline 23 & Valor Presente Ajustado ao Risco \\
\hline 24 & Valor em Liquidação \\
\hline 25 & Valor de Liquidação Futura \\
\hline 26 & Não rotular \\
\hline
\end{tabular}

Fonte: Dados da pesquisa

Um destaque foi que para alguns respondentes não consideram importante o nome a ser colocado, conforme sugere a Canadian Accounting Standards Board (AcSB) "Sugerimos que, uma vez que é quase inevitável que qualquer rótulo seja exposto a má interpretação, a ênfase deve ser colocada na abordagem de mensuração e não na etiqueta. Outra alternativa é simplesmente definir a abordagem de mensuração sem anexar um rótulo". Observa-se ainda uma quantidade expressiva de termos propostos, demonstrando a dificuldade de unificação de conceitos.

Com relação ao Item (a) da Pergunta 5 sobre a definição de "Valor de Saída Atual" 40,37\% dos respondentes não opinarão e que a maioria dos respondentes discordam com a definiç̧ão proposta.

Quadro 12: Nível de concordância por setor de atuação da Pergunta 5a

\begin{tabular}{|l|c|c|c|c|c|c|c|}
\hline & \multicolumn{3}{|c|}{$\begin{array}{c}\text { \% Com relação ao nível de } \\
\text { concordância }\end{array}$} & \multicolumn{2}{c|}{$\begin{array}{c}\text { Concordância em relação ao } \\
\text { Setor de Atuação }\end{array}$} & $\begin{array}{c}\text { Sem } \\
\text { Comentário }\end{array}$ & Total \\
\hline $\begin{array}{l}\text { Setor de } \\
\text { Atuação }\end{array}$ & Concorda & Discordo & $\begin{array}{c}\text { Sem } \\
\text { Comentário }\end{array}$ & Concorda & Discordo & & 56 \\
\hline $\begin{array}{l}\text { Associação } \\
\text { Profissional }\end{array}$ & $34,78 \%$ & $35,62 \%$ & $33,85 \%$ & $14,29 \%$ & $46,43 \%$ & $39,29 \%$ & 5 \\
\hline Auditoria & $0,00 \%$ & $6,85 \%$ & $1,54 \%$ & $0,00 \%$ & $83,33 \%$ & $16,67 \%$ & 6 \\
\hline Empresa & $17,39 \%$ & $23,29 \%$ & $35,38 \%$ & $9,09 \%$ & $38,64 \%$ & $52,27 \%$ & 44 \\
\hline Normatizadores & $39,13 \%$ & $31,51 \%$ & $18,46 \%$ & $20,45 \%$ & $52,27 \%$ & $27,27 \%$ & 44 \\
\hline Rating & $4,35 \%$ & $0,00 \%$ & $1,54 \%$ & $50,00 \%$ & $0,00 \%$ & $50,00 \%$ & 2 \\
\hline Universidade & $0,00 \%$ & $0,00 \%$ & $1,54 \%$ & $0,00 \%$ & $0,00 \%$ & $100,00 \%$ & 1 \\
\hline Usuário & $4,35 \%$ & $2,74 \%$ & $7,69 \%$ & $12,50 \%$ & $25,00 \%$ & $62,50 \%$ & 8 \\
\hline Total Geral & $\mathbf{1 0 0 \%}$ & $\mathbf{1 0 0 \%}$ & $\mathbf{1 0 0 \%}$ & $\mathbf{1 4 , 2 9 \%}$ & $\mathbf{4 5 , 3 4 \%}$ & $\mathbf{4 0 , 3 7 \%}$ & $\mathbf{1 6 1}$ \\
\hline
\end{tabular}

Fonte: Dados da pesquisa

Quadro 13: Nível de concordância por país de origem da Pergunta 5a

\begin{tabular}{|l|c|c|c|c|c|}
\hline & \multicolumn{2}{|c|}{$\begin{array}{c}\text { \% Com relação ao nível de } \\
\text { concordância }\end{array}$} & $\begin{array}{c}\text { \% de Concordância em relação } \\
\text { ao País de Origem }\end{array}$ & Discordo & Total \\
\hline País de Origem & Concorda & Discordo & Concorda & $57 \%$ & 7 \\
\hline África do Sul & $20 \%$ & $9 \%$ & $43 \%$ & $50 \%$ & 8 \\
\hline Austrália & $27 \%$ & $9 \%$ & $50 \%$ & $38 \%$ & 8 \\
\hline Canadá & $33 \%$ & $7 \%$ & $63 \%$ & $90 \%$ & 20 \\
\hline EUA & $13 \%$ & $40 \%$ & $10 \%$ & $94 \%$ & 17 \\
\hline Reino Unido & $7 \%$ & $36 \%$ & $6 \%$ & $\mathbf{7 5 \%}$ & $\mathbf{6 0}$ \\
\hline Total Geral & $\mathbf{1 0 0 \%}$ & $\mathbf{1 0 0 \%}$ & $\mathbf{2 5 \%}$ & & \\
\hline
\end{tabular}

Fonte: Dados da pesquisa

Em relação ao país de origem observa-se que tanto os respondentes dos EUA quanto do Reino Unido discordam em sua maioria com a definição proposta.

Com relação a utilização do termo "Valor de Saída Atual" que trata o item (b) da Pergunta 5, há uma semelhança de opinião dos respondentes em relação ao item (a) que trata da definição desse termo. Ressalta-se que alguns dos respondentes não opinavam nesse item por já terem discordado da definição, conforme a opinião da International Association of Insurance Supervisors (IAIS): "Em 
relação ao melhor rótulo para o atributo de mensuração, não podemos responder a esta pergunta pois está pendente do resultado do trabalho em mensuração a valor justo. O SFAS 157 define o valor justo em termos de um modelo de valor de saída atual. O Conselho estará ciente dos comentários da IAIS ao recente documento de discussão sobre Mensuração a Valor Justo que há certos aspectos deste modelo que acreditamos serem inadequados para a mensuração de passivos de nível 3 da hierarquia (como o uso de crédito próprio características na mensuração e falta de mercados ativos e líquidos para passivos de seguros). Se esses aspectos não forem abordados no trabalho em mensuração de valor justo e, no entanto, os dois termos permanecem semelhantes, a IAIS sugeriria o IASB a usar um rótulo diferente para contratos de seguro".

Quadro 14: Nível de concordância por setor de atuação da Pergunta 5b

\begin{tabular}{|l|c|c|c|c|c|c|c|}
\hline & \multicolumn{3}{|c|}{$\begin{array}{c}\text { \% Com relação ao nível de } \\
\text { concordância }\end{array}$} & \multicolumn{2}{c|}{$\begin{array}{c}\text { Concordância em relação ao } \\
\text { País de Origem }\end{array}$} & $\begin{array}{c}\text { Sem } \\
\text { Comentário }\end{array}$ & Total \\
\hline Setor de Atuação & Concordo & Discordo & $\begin{array}{c}\text { Sem } \\
\text { Comentário }\end{array}$ & Concordo & Discordo & & \\
\hline Associação Profissional & $36,36 \%$ & $32,86 \%$ & $36,23 \%$ & $14,29 \%$ & $41,07 \%$ & $44,64 \%$ & 56 \\
\hline Auditoria & $0,00 \%$ & $7,14 \%$ & $1,45 \%$ & $0,00 \%$ & $83,33 \%$ & $16,67 \%$ & 6 \\
\hline Empresa & $13,64 \%$ & $27,14 \%$ & $31,88 \%$ & $6,82 \%$ & $43,18 \%$ & $50,00 \%$ & 44 \\
\hline Normatizadores & $45,45 \%$ & $28,57 \%$ & $20,29 \%$ & $22,73 \%$ & $45,45 \%$ & $31,82 \%$ & 44 \\
\hline Rating & $0,00 \%$ & $1,43 \%$ & $1,45 \%$ & $0,00 \%$ & $50,00 \%$ & $50,00 \%$ & 2 \\
\hline Universidade & $0,00 \%$ & $0,00 \%$ & $1,45 \%$ & $0,00 \%$ & $0,00 \%$ & $100,00 \%$ & 1 \\
\hline Usuário & $4,55 \%$ & $2,86 \%$ & $7,25 \%$ & $12,50 \%$ & $25,00 \%$ & $62,50 \%$ & 8 \\
\hline Total Geral & $\mathbf{1 0 0 \%}$ & $\mathbf{1 0 0} \%$ & $\mathbf{1 0 0 \%}$ & $\mathbf{1 3 , 6 6 \%}$ & $\mathbf{4 3 , 4 8 \%}$ & $\mathbf{4 2 , 8 6 \%}$ & $\mathbf{1 6 1}$ \\
\hline
\end{tabular}

Fonte: Dados da pesquisa

Os resultados das opiniões entre os países de origem que possui a maioria dos respondentes também são semelhantes quando comparado com a definição, com destaque para África do Sul que todos os respondentes discordaram da definição.

Quadro 15: Nível de concordância por país de origem da Pergunta 5b

\begin{tabular}{|l|c|c|c|c|c|}
\hline & \multicolumn{2}{|c|}{$\begin{array}{c}\text { \% Com relação ao nível de } \\
\text { concordância }\end{array}$} & \multicolumn{2}{c|}{$\begin{array}{c}\text { \%o de Concordância em } \\
\text { relação ao Setor de Atuação }\end{array}$} & \\
\hline País de Origem & Concordo & Discordo & Concordo & Discordo & Total \\
\hline África do Sul & $0 \%$ & $15 \%$ & $0 \%$ & $100 \%$ & 7 \\
\hline Austrália & $43 \%$ & $4 \%$ & $75 \%$ & $25 \%$ & 8 \\
\hline Canadá & $21 \%$ & $11 \%$ & $38 \%$ & $63 \%$ & 8 \\
\hline EUA & $7 \%$ & $41 \%$ & $5 \%$ & $95 \%$ & 20 \\
\hline Reino Unido & $29 \%$ & $28 \%$ & $24 \%$ & $76 \%$ & 17 \\
\hline Total Geral & $\mathbf{1 0 0 \%}$ & $\mathbf{1 0 0 \%}$ & $\mathbf{2 3 \%}$ & $\mathbf{7 7 \%}$ & $\mathbf{6 0}$ \\
\hline
\end{tabular}

Fonte: Dados da pesquisa

\section{CONSIDERAÇÕES FINAIS}

O objetivo da presente pesquisa foi analisar a percepção dos respondentes com relação a mensuração dos contratos de seguros sugeridos pelo DP/2007/1 - Preliminary Views on Insurance Contracts.

Ao avaliar o nível de concordância dos respondentes em relação a proposta do IASB, não há um consenso dominante das opiniões, apresentando mais discordâncias que concordância. Prevalecendo com uma aceitação a proposta de utilizar uma mensuração em três blocos, mas ainda assim com sugestão de melhorias nesse processo ou desejando obter informações mais claras.

Os respondentes que emitiram opiniões acerca das definições e termos utilizados na proposta apresentaram pontos de vistas negativos e sugerem outras definições ou a utilização de outros termos para indicar o "Valor de Saída Atual". Essa situação é percebida pela quantidade de termos sugeridos e uma falta de aceitação da maioria dos respondentes. Os mesmos resultados são percebidos com relação ao nível de detalhes que foi apresentado como orientação ao fluxo de caixa e margem de risco. Sendo um ponto de atenção entre os países que utilizam o FASB em sua prática contábil é que deveria 
conter mais informações e exemplos podendo relacionar a essas sugestões o fato de usar normas baseados em regras e não em princípios como é desejado pelo próprio IASB.

Entre as alternativas de calibração do prêmio em função da margem de risco houve uma preferência por uma opção que permita um julgamento para cada caso e utilizando o teste de adequação de passivo para ajustar os valores conforme a mudança de ambiente, não deixando que o processo fique engessado. Uma preocupação dos respondentes é de não conseguirem aplicar na prática os itens propostos devido as particularidades existentes no mercado de seguros.

A discussão em torno da mensuração a valor justo para contratos de seguros ainda carece de mais estudos. Algumas pesquisas tem testado a contabilização a valor justo considerando a hierarquia em três níveis para a mensuração de instrumentos financeiros, tais pesquisas ainda não apontam para uma mesma direção o que demonstra a dificuldade da mensuração a valor justo com destaque para a avaliação de itens do balanço que não possuem um mercado ativo onde fica a cargo da própria entidade estabelecer critérios que podem sugerir manipulação dos dados e isso também fícou evidente nas opiniões dos respondentes quando o IASB propõe uma mensuração utilizando o fluxo de caixa descontado e margem de risco.

A pesquisa limitou-se ao capitulo 3 do DP/2007/1 que trada da mensuração dos contratos de seguros, mas especificamente aos passivos de seguros, buscando apenas as opiniões ou sugestões dos respondentes presentes nas comments letters não comparando o resultado dessas opiniões com documentos posteriores emitidos pelo IASB. Dessa forma, pesquisas futuras podem ser aplicadas para comparar o nível de adesão pelo IASB dos comentários feitos mercado segurador, na busca da existência de lobby ou ainda pode-se estudar a aderência (ou falta de) das propostas em torno dos reconhecimento e divulgação dos contratos de seguros também constantes no DP/2007/1.

\section{REFERÊNCIAS}

BARDIN, L. Análise de conteúdo. 3. Ed. Reimp. Lisboa: Edições, v. 70, 2011.

BARTH, M. E. Global financial reporting: Implications for U.S. academics. The Accounting Review, V.83, n. 5, p.1159-1179, 2008.

BARTH, M.; TAYLOR, D. In defense of fair value: Weithing the evidence on earnings management and asset securitizations. Journal of Accounting and Economics. Doi:10.1016/j.jacceco.2009.10.001.

BARTH, M., BEAVER, W., LANDSMAN, W.; The relevance of the value relevance literature for financial accounting standard setting: Another view. Journal of Accounting and Economics, V.31. 77-104, 2001.

BLOOMER, J. Impact of Insurance Accounting on Business Reality and Financial Stability. The Geneva Papers on Risk and Insurance-Issues and Practice, v. 29, n. 1, p. 56-62, 2004.

CAS FAIR VALUE STEERING COMMITTEE et al. Fair Value of P\&C Liabilities: Practical Implications. In: Casualty Actuarial Society. 2004.

CRISTEA, V. G. The necessity to introduce the accounting rules and fair value in the conceptual framework. Procedia Economics and Finance, v. 26, n. 15, p. 515- 521, 2015.

Dias, E. H. O. M. Fair Value: Princípios e aplicações a uma carteira de seguros do ramo vida. Dissertação de Mestrado. Universidade Técnica de Lisboa. Instituto Superior de Economia e Gestão, 2005.

FORNARO, J. M.; BARBERA, A. T. The new fair value hierarchy: Key provisions, implications, and effect on information usefulness. Review of Business, v. 28, n. 1, p. 31-37, 2007.

HENDRIKSEN, E. S.; VAN BREDA, M. F. Teoria da contabilidade; Tradução de Antônio Zoratto Sanvicente. São Paulo: Atlas, p. 277-297, 1999. 
IASB - International Accounting Standards Board. IFRS standard 17: Insurance contracts. London: IFRS Foundation, 2017.

IASB - International Accounting Standards Board. IFRS standards basis for conclusions: IFRS 17 insurance contracts. London: IFRS Foundation, 2017.

IASB - International Accounting Standards Board. Discussion paper: Preliminary views on insurance contracts London. IFRS Foundation, 2007.

IASB - International Accounting Standards Board. Exposure draft ED/2010/8: Insurance contracts. IFRS Foundation, 2008.

IJIRI, Y.; THOMPSON, G. L. Applications of mathematical control theory to accounting and budgeting (the continuous wheat trading model). The Accounting Review, v. 45, n. 2, p. 246-258, 1970.

KING, A.M. Fair value is dangerous for cost management. Cost management, jan/feb 2009; 23; 1; ABI/INFORM Global.

MARQUES, T. O. Informações a valor justo: o atendimento às características qualitativas das estruturas conceituais da contabilidade na perspectiva dos resultados de estudos empíricos. Tese de doutorado - Programa Multi-institucional e Inter-regional de Pós-Graduação em Ciências Contábeis (UNB/UFBP/UFRN), Universidade de Brasília, Distrito Federal, Brasil. 2017.

MCCARTY, R. J. Federal valuation of railroad property. Tiernan-Dart Company, 1915.

MONTAGUE, N.R. The effects of directional audit guidance and estimation uncertainty on auditor confirmation bias and professional skepticism when evaluating fair value estimates, Business Administration. 2010.

MOONITZ, M. The basic postulates of accounting. American Institute of CPAs, 1961.

NEVES, J. L. Pesquisa qualitativa: características, usos e possibilidades. Caderno de pesquisas em administração, São Paulo, v. 1, n. 3, p. 2, 1996.

NIYAMA, J. K.; SILVA, C. A. T. Teoria avançada da contabilidade. São Paulo: Atlas, p. 38-66, 2014.

PROCHÁZKA, D. The role of fair value measurement in the recent financial crunch, economics, Management and financial markets, vol. 6, n. 1, pp. 989-989-1001.2011.

RYAN, S. G. Accounting in and for the subprime crisis. The Accounting Review, v. 83, n. 6, p. 1605-1638, 2008.

SILVA, J. P. Análise da percepção dos usuários da informação contábil sobre a proposta de revisão da estrutura conceitual do IASB. 2014. 194 f., il. Dissertação (Mestrado em Ciências Contábeis) - Programa Multi-institucional e Inter-Regional de Pós-Graduação em Ciências Contábeis, Universidade de Brasília, Universidade Federal da Paraíba, Universidade Federal do Rio Grande do Norte, Brasília, 2014.

SPROUSE, R. T.; MOONITZ, M. A tentative set of broad accounting principles for business enterprises. American Institute of CPAs, 1962.

STEVENS, S. S. Mathematics, measurement and psychophysics. Handbook of experimental psychology. New York: S. Stevens, 1951.

VANDERHOOF, I. T.; ALTMAN, E. The fair value of insurance liabilities. Springer Science \& Business Media, 2013. 
WANDERSON ARAÚJO FERNANDES é mestrando em Ciências Contábeis/UnB, especialista em Controladoria e Finanças/UnB e graduado em Ciências Contábeis/ICSP. Professor na Universidade Estácio de Sá/Brasília.

E-mail: fernandeswa@hotmail.com

MILLENA CORDEIRO DA SILVA é mestranda em Ciências Contábeis/UnB e graduada em Ciências Contábeis/UFF.

E-mail: millena.cordeiro@gmail.com

JEREMIAS PEREIRA DA SILVA ARRAES é mestre em Administração/UnB, especialista em Auditoria Interna e Externa/ICAT-DF e em Controle e Auditoria Pública/FMBH e graduado em Ciências Contábeis/ULBRA. Professor substituto na UnB.

E-mail: jeremias@unb.br 